\title{
Mortality, stroke, and heart failure in atrial fibrillation cohorts after ablation versus propensity-matched cohorts
}

This article was published in the following Dove Press journal:

Pragmatic and Observational Research

29 May 2017

Number of times this article has been viewed

\author{
Julian WE Jarman' \\ Tina D Hunter ${ }^{2}$ \\ Wajid Hussain' \\ Jamie L March ${ }^{3}$ \\ Tom Wong' \\ Vias Markides'
}

'Cardiology \& Electrophysiology, Heart Rhythm Centre, NIHR

Cardiovascular Research Unit,

The Royal Brompton Hospital, and

National Heart and Lung Institute,

Imperial College, London, UK; ${ }^{2}$ Health

Outcomes Research, CTI Clinical

Trial and Consulting Services, Inc.,

Cincinnati, $\mathrm{OH},{ }^{3} \mathrm{Health}$ Economics

and Market Access, Biosense Webster,

Inc., Diamond Bar, CA, USA
Correspondence: Tina D Hunter

CTI Clinical Trial and Consulting Services, Inc., 1775 Lexington Avenue,

Suite 200, Cincinnati, OH 452I2, USA

Tel + I 5135989290

Fax +I 5137581710

Email thunter@ctifacts.com
Background: We sought to determine from key clinical outcomes whether catheter ablation of atrial fibrillation (AF) is associated with increased survival.

Methods and results: Using routinely collected hospital data, ablation patients were matched to two control cohorts using direct and propensity score methodology. Four thousand nine hundred ninety-one ablation patients were matched 1:1 with general AF controls without ablation. Five thousand four hundred seven ablation patients were similarly matched to controls who underwent cardioversion. We examined the rates of ischemic stroke or transient ischemic attack (stroke/TIA), heart failure hospitalization, and death. Matched populations had very similar comorbidity profiles, including nearly identical $\mathrm{CHA}_{2} \mathrm{DS}_{2}$-VASc risk distribution $(p=0.6948$ and $p=0.8152$ vs general AF and cardioversion cohorts). Kaplan-Meier models showed increased survival after ablation for all outcomes compared with both control cohorts $(p<0.0001$ for all outcomes vs general AF, $p=0.0087$ for stroke/TIA, $p<0.0001$ for heart failure, and $p<0.0001$ for death vs cardioversion). Cox regression models also showed improved survival after ablation for all outcomes compared with the general AF cohort (hazard ratio $[\mathrm{HR}]=0.4,95 \%$ confidence interval [95\% CI]: $0.3-0.6, p<0.0001$ for stroke/TIA; HR=0.4, 95\% CI: $0.2-0.6, p<0.0001$ for heart failure; $\mathrm{HR}=0.1,95 \% \mathrm{CI}: 0.1-0.1, p<0.0001$ for death) and the cardioversion cohort (HR=0.6 , 95\% CI: $0.4-0.9, p=0.0111$ for stroke/TIA; HR=0.4, 95\% CI: $0.3-0.6, p<0.0001$ for heart failure; $\mathrm{HR}=0.3,95 \% \mathrm{CI}: 0.2-0.5, p<0.0001$ for death).

Conclusions: Catheter ablation of AF was associated with very significant reductions in mortality, stroke/TIA, and heart failure compared with a matched general AF population and a matched population who underwent cardioversion. Potential confounding of outcomes was minimized by very tight cohort matching.

Keywords: atrial fibrillation, catheter ablation, cardioversion, ischemic stroke, heart failure

\section{Introduction}

Atrial fibrillation (AF) is a powerful independent risk factor for death, ${ }^{1}$ ischemic stroke ${ }^{2}$ heart failure, ${ }^{3}$ and reduced quality of life. ${ }^{4}$ It is unclear whether sinus rhythm restoration improves these outcomes. Randomized testing of rhythm control with drugs and cardioversion did not demonstrate mortality benefit over rate control ${ }^{5}$; however, subsequent analyses suggest that the benefit of sinus rhythm has been offset by the deleterious effects of antiarrhythmic drugs and inappropriate interruption of anticoagulation. ${ }^{6}$ More recent trials have shown reduction in cardiovascular hospitalization or death with newer antiarrhythmics. ${ }^{7}$ 
Catheter ablation of AF has proven superior to antiarrhythmic drugs at maintaining sinus rhythm in multiple randomized trials. ${ }^{8,9}$ However, procedural complications are possible ${ }^{10}$ and the effect on key clinical outcomes is unknown ${ }^{11}$; thus, it is indicated in guidelines only for symptom control. ${ }^{12,13}$ Although results of large randomized trials to assess the impact on clinical outcomes - Catheter Ablation versus Antiarrhythmic Drug Therapy for Atrial Fibrillation Trial (CABANA) and Early Treatment of Atrial Fibrillation for Stroke Prevention Trial (EAST) - are awaited, studies using nonrandomized methodologies of increasing sophistication have addressed the question. ${ }^{14-18}$

We utilized a retrospective cohort design with very large and well-matched cohorts to study the rates of ischemic stroke or transient ischemic attack (stroke/TIA), heart failure hospitalization, and death in hospital for AF patients having catheter ablation in the United Kingdom (UK) compared with AF patients undergoing cardioversion and with a more general AF cohort.

\section{Methods}

\section{Data source}

The data source was the Hospital Episode Statistics (HES) database. HES contains over 125 million records annually, comprising all National Health Service (NHS) inpatient episodes, outpatient appointments, and emergency department attendances in England.

The particular dataset utilized for this study included anonymized health records for inpatient and outpatient hospital visits from 1996 to the end of 2013. Within the UK, outpatient visits include office visits for medical specialty care. This source data contained demographics, chronology, primary diagnosis, and procedure codes for each visit, and indicators of the occurrence of other key diagnoses and procedures of interest, whether primary or secondary. The diagnoses and procedures of interest were defined at each visit by observation of recorded International Classification of Diseases, 10th Revision (ICD-10) and Office of Population Censuses and Surveys (OPCS) Classification of Surgical Interventions and Procedures, 4th Revision (OPCS-4) codes.

\section{Patient selection}

All patients in the study were required to have their first record of AF (ICD-10 code I48) seen during or after April 2005 with at least one record of AF observed during or after 2008 in order to assure a contemporary population. Patient cohorts included subsets of patients with or without treatment with pulmonary vein ablation (PVA), meaning percutaneous transluminal AF ablation incorporating pulmonary vein isolation. Patients with evidence of valvular disease or confounding pacing or ablation procedures, as discerned via ICD-10 or OPCS-4 codes, were excluded (Supplementary Table).

\section{Cohort definition}

In addition to the general inclusion and exclusion criteria, three cohorts were identified through the application of cohort-specific criteria. The treatment cohort of interest, the PVA cohort, was required to have a record of percutaneous transluminal PVA for AF (ICD-10 procedure code K621) concurrent with a primary diagnosis of $\mathrm{AF}$, and with no other type of catheter or surgical ablation of the heart prior to the first PVA meeting these criteria (Supplementary Table). The general AF control cohort was required to have a minimum of two episode records with no record of any catheter or surgical ablation at any time. The cardioversion cohort was the subset of the general AF control cohort with a primary procedure code for direct current cardioversion (OPCS4 procedure code X501 or X502) recorded with a primary diagnosis code for AF.

\section{Definitions of timing, risk factors, and outcomes}

The index date, or "time zero," after which all outcomes were measured, was defined as the first PVA for the ablation cohort, the second hospital record for the AF control cohort, and the first cardioversion for the cardioversion cohort.

Risk factors at baseline were defined via diagnosis and procedure codes observed within 3 years prior to the index date (Supplementary Table). These risk factors include stroke or TIA, hypertension, diabetes, heart failure, peripheral vascular disease, coronary artery disease, sleep apnea, hemorrhagic stroke, cardiomyopathy, obesity, other arrhythmias or conduction disorders, chronic kidney disease, chronic obstructive pulmonary disease, hyperlipidemia, and pulmonary disease. In addition, coronary artery bypass graft and percutaneous coronary intervention procedures were included as evidence of vascular disease. $\mathrm{CHADS}_{2}$ and $\mathrm{CHA}_{2} \mathrm{DS}_{2}-$ VASc scores ${ }^{19,20}$ for stroke risk were also calculated.

The outcomes of interest were the diagnosis of ischemic stroke/TIA (ICD-10 diagnosis codes I63-I64x, G45), inpatient hospitalization for heart failure (ICD-10 diagnosis codes I50, I110, I130, I132), and all-cause inpatient death.

In addition to the occurrence of stroke, heart failure, and death, the timing of these outcomes was also of interest. All events occurring on or after a patient's index date were considered to be the outcomes of interest, with the first occurrence of each event type defined as the survival outcome. 


\section{Cohort matching}

To reduce selection bias and create cohorts of clinically wellmatched patients, a combination of propensity and direct matching was used to match ablation patients in a 1:1 ratio with patients in the general AF control cohort, and separately with patients in the cardioversion cohort.

Propensity scores, defined as the patients' probabilities of having PVA treatment given their individual profile of observed characteristics at or prior to their index date, were calculated separately for each control cohort via logistic regression models. These models used 17 baseline comorbid condition indicators as potential predictors, including diagnoses of ischemic stroke or TIA, hemorrhagic stroke, hypertension, diabetes, heart failure, hyperlipidemia, peripheral vascular disease, coronary artery disease, sleep apnea, cardiomyopathy, obesity, other arrhythmias, chronic kidney disease, chronic obstructive pulmonary disease, and other pulmonary diseases, as well as coronary artery bypass graft and percutaneous coronary intervention procedures. Baseline indicators for each comorbidity were defined as any record of the condition within 3 years prior to a patient's index date. Stepwise selection was used to retain only conditions that significantly impacted treatment cohort as covariates within each logistic model. The resulting sets of propensity scores summarize each patient's individual probability of being in the ablation cohort versus the control cohort.

The two sets of propensity scores, one for each control group, were used simultaneously with several additional metrics to match ablation patients with general AF patients, and separately with cardioversion patients. An SAS macro called gmatch, developed by the Mayo Clinic Biomedical Statistics and Informatics Division, was used to match patients in a 1:1 ratio on age, sex, calendar year of index date, and time from AF diagnosis to index date, as well as on the resulting comorbidity-based propensity scores. ${ }^{21}$

\section{Statistical models}

Survival analysis methods, including Kaplan-Meier and Cox regression, were used to model the time to event for each of the three outcomes of interest. These methods correctly incorporate the information from both censored and uncensored patients, with censored patients defined as those with no event through 2013. Stroke/TIA outcomes that occurred on the index date through day 6 postindex were excluded from statistical models in order to avoid violating the proportional hazard assumption via inclusion of treatment-related events, but are reported separately.
Product limit estimates of the cumulative proportion of patients experiencing stroke/TIA, heart failure hospitalization, and death in a hospital setting were calculated at yearly intervals, by matched cohorts, using Kaplan-Meier survival models. Kaplan-Meier models are unadjusted nonparametric models of time-to-event outcomes as a function of a single predictor variable. Thus, six models were used to model the three outcomes of interest for each of the two matched populations, with cohort as the single predictor in each model.

Hazard ratios (HRs) for treatment cohort, as well as for additional statistically significant predictors of stroke/TIA, heart failure, and death, were also derived from multivariable Cox regression models. Again, a total of six models were used, in this case to produce adjusted HR estimates. The confounders retained in each model were chosen via stepwise selection from among age, sex, index year, and all comorbid risks observed within 3 years prior to the index date, as defined previously.

All statistical analyses in this study were performed using SAS software, version 9.2 (SAS Institute, Inc., Cary, NC, USA). All data used to perform this analysis were de-identified and accessed in compliance with the Health Insurance Portability and Accountability Act. As a retrospective analysis of a de-identified database, the research was exempt from the Institutional Review Board review under 45 CFR 46.101(b) (4).

\section{Results}

A total of 1,409,106 patients had a diagnosis of AF within the required timeframes for the study. Of these $\mathrm{AF}$ patients, 6,356 met all inclusion and exclusion criteria for the catheter ablation cohort. An additional 81,189 patients met all criteria for inclusion in the cardioversion cohort, and 1,312,339 patients met the criteria for remaining in the general AF cohort. These cohorts were then used for matching ablation patients with similar cardioversion patients, and separately with similar general AF patients.

\section{Matched cohorts}

The final analysis populations included 4,991 patients from the PVA cohort that were matched 1:1 with patients from the general AF control cohort, and 5,407 PVA patients similarly matched with patients from the cardioversion control cohort. Each matched population had very similar demographic and comorbidity profiles across cohorts (Table 1). In addition, both the $\mathrm{CHADS}_{2}$ and $\mathrm{CHA}_{2} \mathrm{DS}_{2}$-VASc risk score profiles were nearly identical across the PVA versus general AF match ( $p=0.5588$ and $p=0.6948$, respectively) and across the PVA versus cardioversion match $(p=0.7428$ and $p=0.8152$, 
Table I Baseline patient characteristics

\begin{tabular}{|c|c|c|c|c|}
\hline & \multicolumn{2}{|c|}{$\begin{array}{l}\text { PVA vs AF match } \\
\text { ( } N=4,99 \text { I per cohort) }\end{array}$} & \multicolumn{2}{|c|}{$\begin{array}{l}\text { PVA vs } C V \text { match } \\
\text { ( } N=5,407 \text { per cohort) }\end{array}$} \\
\hline & PVA & AF Control & PVA & CV Control \\
\hline \multicolumn{5}{|l|}{ Comorbid condition $^{\mathrm{a}}$} \\
\hline Arrhythmias - other than AF & $1.7 \%$ & $1.7 \%$ & $0.8 \%$ & $0.6 \%$ \\
\hline Chronic obstructive pulmonary disease & $1.7 \%$ & $1.6 \%$ & $1.7 \%$ & $1.4 \%$ \\
\hline Chronic kidney disease & $0.7 \%$ & $0.6 \%$ & $1.4 \%$ & $1.5 \%$ \\
\hline Diabetes & $5.5 \%$ & $5.3 \%$ & $5.5 \%$ & $5.3 \%$ \\
\hline Heart failure & $0.5 \%$ & $0.4 \%$ & $0.6 \%$ & $0.5 \%$ \\
\hline Hyperlipidemia & $15.2 \%$ & $15.0 \%$ & $16.7 \%$ & $16.6 \%$ \\
\hline Hypertension & $33.4 \%$ & $33.1 \%$ & $37.4 \%$ & $37.5 \%$ \\
\hline Obesity & $2.2 \%$ & $2.4 \%$ & $3.0 \%$ & $2.9 \%$ \\
\hline Stroke (ischemic) or TIA & $1.4 \%$ & $1.5 \%$ & $1.9 \%$ & $1.8 \%$ \\
\hline Stroke (ischemic) & $0.8 \%$ & $1.3 \%$ & $1.1 \%$ & $1.3 \%$ \\
\hline TIA & $0.7 \%$ & $0.2 \%$ & $0.9 \%$ & $0.6 \%$ \\
\hline Vascular disease & $14.8 \%$ & $14.4 \%$ & $13.5 \%$ & $13.2 \%$ \\
\hline \multicolumn{5}{|l|}{ Age group (years) } \\
\hline$<35$ & $3.0 \%$ & $3.2 \%$ & $2.6 \%$ & $2.6 \%$ \\
\hline $35-44$ & $9.1 \%$ & $8.8 \%$ & $8.1 \%$ & $8.1 \%$ \\
\hline $45-54$ & $22.6 \%$ & $22.5 \%$ & $21.5 \%$ & $21.4 \%$ \\
\hline $55-64$ & $35.9 \%$ & $36.2 \%$ & $37.3 \%$ & $37.4 \%$ \\
\hline $65-74$ & $25.4 \%$ & $24.9 \%$ & $26.4 \%$ & $26.4 \%$ \\
\hline $75-84$ & $4.0 \%$ & $4.2 \%$ & $4.0 \%$ & $4.0 \%$ \\
\hline$\geq 85$ & $0.1 \%$ & $0.2 \%$ & $0.1 \%$ & $0.1 \%$ \\
\hline \multicolumn{5}{|l|}{ Gender } \\
\hline Female & $30.9 \%$ & $30.9 \%$ & $29.6 \%$ & $29.6 \%$ \\
\hline Male & $69.1 \%$ & $68.9 \%$ & $70.4 \%$ & $70.4 \%$ \\
\hline Undetermined & $0.0 \%$ & $0.2 \%$ & $0.0 \%$ & $0.0 \%$ \\
\hline \multicolumn{5}{|l|}{ Year of the index date } \\
\hline 2007 & $2.0 \%$ & $2.3 \%$ & $2.0 \%$ & $1.9 \%$ \\
\hline 2008 & $6.8 \%$ & $6.5 \%$ & $6.4 \%$ & $6.7 \%$ \\
\hline 2009 & $10.2 \%$ & $10.5 \%$ & $9.7 \%$ & $9.4 \%$ \\
\hline 2010 & $12.7 \%$ & $13.9 \%$ & $12.8 \%$ & $12.8 \%$ \\
\hline 2011 & $17.8 \%$ & $17.7 \%$ & $17.5 \%$ & $17.4 \%$ \\
\hline 2012 & $23.4 \%$ & $23.2 \%$ & $23.3 \%$ & $23.4 \%$ \\
\hline 2013 & $24.9 \%$ & $24.3 \%$ & $26.3 \%$ & $26.3 \%$ \\
\hline 2014 & $2.3 \%$ & $1.6 \%$ & $2.1 \%$ & $2.1 \%$ \\
\hline \multicolumn{5}{|l|}{ Days from the first $A F$ to index date } \\
\hline Mean & 450 & 444 & 630 & 165 \\
\hline Median & 284 & 278 & 399 & 0 \\
\hline Interquartile range & 676 & 678 & 991 & 393 \\
\hline \multicolumn{5}{|l|}{ Months of follow-up after the index date } \\
\hline Mean & 28.1 & 28.9 & 27.5 & 27.8 \\
\hline Median & 24.0 & 25.0 & 24.0 & 23.0 \\
\hline Interquartile range & $11-42$ & $12-44$ & ||$-4 \mid$ & $11-42$ \\
\hline \multicolumn{5}{|l|}{$\mathrm{CHA}_{2} \mathrm{DS}_{2}$-VASc risk score } \\
\hline 0 & $34.6 \%$ & $33.8 \%$ & $33.5 \%$ & $33.5 \%$ \\
\hline 1 & $30.9 \%$ & $31.7 \%$ & $30.6 \%$ & $30.8 \%$ \\
\hline 2 & $19.4 \%$ & $19.9 \%$ & $19.8 \%$ & $20.0 \%$ \\
\hline 3 & $10.3 \%$ & $10.1 \%$ & $11.1 \%$ & $10.9 \%$ \\
\hline 4 & $3.4 \%$ & $3.4 \%$ & $3.6 \%$ & $3.8 \%$ \\
\hline 5 & $1.2 \%$ & $0.9 \%$ & $1.2 \%$ & $0.9 \%$ \\
\hline 6 & $0.2 \%$ & $0.1 \%$ & $0.2 \%$ & $0.1 \%$ \\
\hline$\geq 7$ & $0.0 \%$ & $0.0 \%$ & $0.0 \%$ & $0.0 \%$ \\
\hline
\end{tabular}

Notes: ${ }^{2}$ Comorbid conditions denote a diagnosis recorded within 3 years prior to the index date.

Abbreviations: AF, atrial fibrillation; CV, cardioversion; PVA, pulmonary vein ablation; TIA, transient ischemic attack. 
A

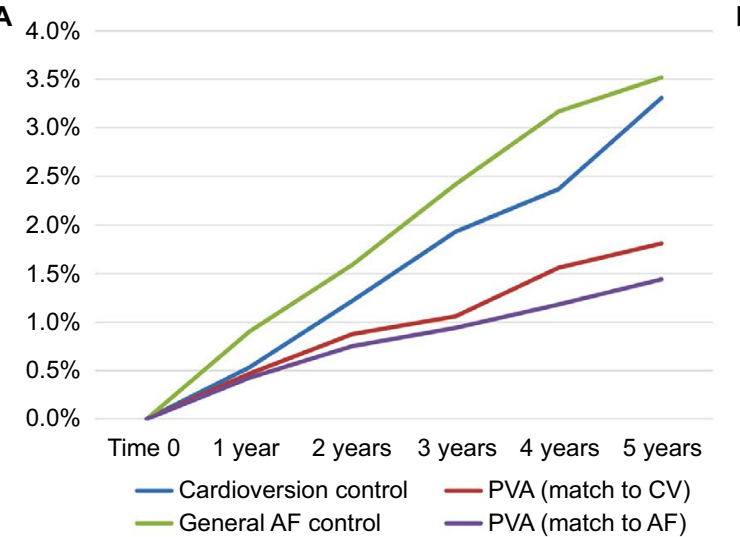

B $4.0 \%$

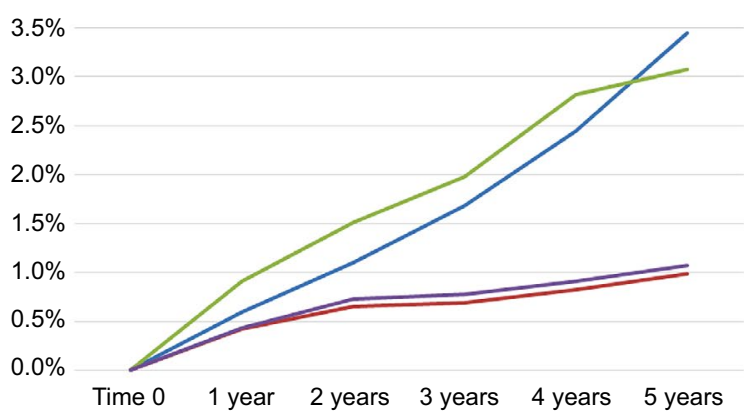

- Cardioversion control _PVA (match to CV) - General AF control $\quad$ PVA (match to AF)

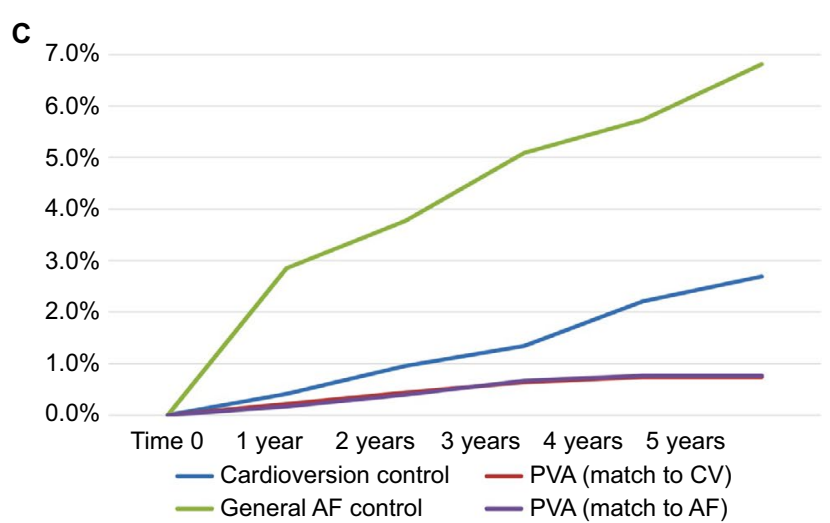

Figure I (A) Product limit survival estimates for stroke events. (B) Product limit survival estimates for heart failure events. (C) Product limit survival estimates for death in a hospital setting.

Abbreviations: AF, atrial fibrillation; CV, cardioversion; PVA, pulmonary vein ablation.

respectively) ( $\mathrm{CHA}_{2} \mathrm{DS}_{2}$-VASc, Table 1, Figure S1A, B). Patients at low risk for stroke, as defined by a $\mathrm{CHA}_{2} \mathrm{DS}_{2}$-VASc score $<2$, comprised nearly two-thirds of the population in each matched cohort (Table 1).

Each matched patient pair in each of the two matched populations was of the same sex, had index visits within one calendar year, and had propensity scores within 0.0001 . The PVA versus general $\mathrm{AF}$ control matches were also within 2 years in age at their index date and within 6 months in length of time from initial AF diagnosis to the index date. The PVA versus cardioversion control matches were within 1 year of the same age at their index date. Available follow-up time from index through 2013 was also similar across cohorts for both matches because of matching on the index year (Figure S2A, B). Median follow-up time was 24 months in both matched AF cohorts, 23 months in the matched cardioversion controls, and 25 months in the matched general AF controls (Table 1).

\section{Survival models}

Kaplan-Meier models show that treatment with PVA is associated with reductions in both stroke and heart failure events, as well as deaths in a hospital setting. In the matched
PVA versus general AF cohorts, all $p$-values for statistical significance of treatment cohort are $<0.0001$. For the PVA versus cardioversion match, $p$-values range from 0.0087 for the stroke endpoint to $<0.0001$ for the heart failure and death endpoints. Product limit survival estimates of cumulative event rates for each outcome are plotted by year in Figure $1 \mathrm{~A}-\mathrm{C}$.

Cox regression models confirm that even after further adjustment for baseline risk factors, PVA is highly predictive of improved survival for each of the stroke, heart failure, and death outcomes, compared with either control cohort. $p$-Values range from 0.011 for stroke in the PVA versus cardioversion matched population to $<0.0001$ for stroke in the PVA versus general AF matched population, and $<0.0001$ for both heart failure hospitalization and death in hospital for both matches. Baseline patient characteristics with statistical significance at the 0.1 level are shown in Tables 2-4, with $p$-values and HRs for each.

The stroke/TIA rates from the index date through day 6 , which were not included in the survival models, were higher in the general AF cohort than in the matched PVA cohort (22 vs 10 events, $\mathrm{N}=4,991$ each) and were lower in the 
Table 2 Cox regression models for stroke events

\begin{tabular}{lll}
\hline & $\begin{array}{l}\text { Chi-square } \\
\text { p-value }\end{array}$ & $\begin{array}{l}\text { Hazard ratio } \\
\text { (95\% confidence } \\
\text { interval) }\end{array}$ \\
\hline Significant predictors (PVA vs AF match, N=I0,8I4) & \\
Cohort (PVA vs AF control) & $<0.000 \mathrm{I}$ & $0.4(0.3-0.6)$ \\
Age & $<0.000 \mathrm{I}$ & $\mathrm{I} .0(\mathrm{I} .0-\mathrm{I} . \mathrm{I})$ \\
Diabetes & 0.0903 & $\mathrm{I} .7(0.9-3.0)$ \\
Peripheral vascular disease & 0.0820 & $2.1(0.9-4.8)$ \\
Prior stroke/TIA & 0.0004 & $4.1(\mathrm{I} .9-8.8)$ \\
Significant predictors (PVA vs CV match, N=9,982) & \\
Cohort (PVA vs CV control) & $0.01 \mathrm{II}$ & $0.6(0.4-0.9)$ \\
Age & 0.0733 & $\mathrm{I} .0(\mathrm{I} .0-1.0)$ \\
Cardiomyopathy & $0.010 \mathrm{I}$ & $3.8(\mathrm{I} .4-10.5)$ \\
Coronary artery bypass graft & 0.0180 & $5.6(1.3-23.4)$ \\
Diabetes & 0.0322 & $1.9(\mathrm{I} .1-3.5)$ \\
Hyperlipidemia & $0.047 \mathrm{I}$ & $\mathrm{I} .5(\mathrm{I} .0-2.3)$ \\
Prior stroke/TIA & 0.0052 & $3.0(\mathrm{I} .4-6.6)$ \\
Sex (male vs female) & 0.0206 & $0.6(0.4-0.9)$ \\
\hline
\end{tabular}

Notes: ${ }^{\mathrm{a}} \mathrm{Age}$ is at the index date and all comorbid conditions include diagnoses within 3 years prior.

Abbreviations: $\mathrm{AF}$, atrial fibrillation; $\mathrm{CV}$, cardioversion; PVA, pulmonary vein ablation; TIA, transient ischemic attack.

Table 3 Cox regression models for heart failure events

\begin{tabular}{|c|c|c|}
\hline & $\begin{array}{l}\text { Chi-square } \\
\text { p-value }\end{array}$ & $\begin{array}{l}\text { Hazard ratio } \\
\text { ( } 95 \% \text { confidence } \\
\text { interval) }\end{array}$ \\
\hline \multicolumn{3}{|c|}{ Significant predictors (PVA vs AF match, $N=|0,8| 4)^{\mathrm{a}}$} \\
\hline Cohort (PVA vs AF control) & $<0.0001$ & $0.4(0.2-0.6)$ \\
\hline Age & 0.0002 & $1.0(1.0-1.1)$ \\
\hline $\begin{array}{l}\text { Chronic obstructive pulmonary } \\
\text { disease }\end{array}$ & 0.0640 & $2.2(1.0-4.9)$ \\
\hline Coronary artery disease & $<0.0001$ & $2.6(1.7-4.0)$ \\
\hline Diabetes & 0.0731 & $1.7(1.0-3.1)$ \\
\hline Heart failure & $<0.0001$ & $24.6(12.8-47.2)$ \\
\hline Hyperlipidemia & 0.0130 & $0.5(0.3-0.9)$ \\
\hline $\begin{array}{l}\text { Percutaneous coronary } \\
\text { intervention }\end{array}$ & 0.0500 & $2.8(1.0-8.0)$ \\
\hline \multicolumn{3}{|c|}{ Significant predictors (PVA vs CV match, $N=9,982)^{a}$} \\
\hline Cohort (PVA vs CV control) & $<0.0001$ & $0.4(0.3-0.6)$ \\
\hline Age & 0.0017 & $1.0(1.0-1.1)$ \\
\hline Chronic kidney disease & 0.0312 & $2.7(1.1-6.8)$ \\
\hline $\begin{array}{l}\text { Chronic obstructive pulmonary } \\
\text { disease }\end{array}$ & 0.0187 & $2.8(1.2-6.4)$ \\
\hline Coronary artery disease & 0.0897 & $1.5(0.9-2.4)$ \\
\hline Heart failure & $<0.0001$ & $6.8(2.7-17.2)$ \\
\hline Obesity & 0.0058 & $2.6(1.3-5.3)$ \\
\hline $\begin{array}{l}\text { Percutaneous coronary } \\
\text { intervention }\end{array}$ & $0.075 I$ & $2.6(0.9-7.7)$ \\
\hline
\end{tabular}

Notes: ${ }^{\mathrm{A}} \mathrm{Age}$ is at the index date and all comorbid conditions include diagnoses within 3 years prior.

Abbreviations: AF, atrial fibrillation; $\mathrm{CV}$, cardioversion; PVA, pulmonary vein ablation.

cardioversion cohort than in the matched PVA cohort (5 vs 15 events, $\mathrm{N}=5,407$ each). In each of the four cohorts, the majority of these acute events occurred on the index date.
Table 4 Cox regression models for death in hospital

\begin{tabular}{|c|c|c|}
\hline & $\begin{array}{l}\text { Chi-square } \\
\text { p-value }\end{array}$ & $\begin{array}{l}\text { Hazard ratio } \\
\text { (95\% confidence } \\
\text { interval) }\end{array}$ \\
\hline \multicolumn{3}{|c|}{ Significant predictors (PVA vs AF match, $N=|0,8| 4)^{a}$} \\
\hline Cohort (PVA vs AF control) & $<0.0001$ & $0.1(0.1-0.1)$ \\
\hline Age & $<0.0001$ & I.I (I.I-I.I) \\
\hline Cardiomyopathy & 0.0961 & $5.3(0.7-38.1)$ \\
\hline Chronic kidney disease & 0.0067 & $2.7(1.3-5.6)$ \\
\hline $\begin{array}{l}\text { Chronic obstructive pulmonary } \\
\text { disease }\end{array}$ & $<0.0001$ & $3.2(1.9-5.4)$ \\
\hline Hyperlipidemia & 0.0597 & $0.7(0.5-1.0)$ \\
\hline Obesity & 0.0482 & $1.9(1.0-3.6)$ \\
\hline $\begin{array}{l}\text { Percutaneous coronary } \\
\text { intervention }\end{array}$ & 0.0228 & $2.8(1.2-6.9)$ \\
\hline Peripheral vascular disease & 0.0219 & $2.0(1.1-3.6)$ \\
\hline \multicolumn{3}{|c|}{ Significant predictors (PVA vs CV match, $N=9,982)^{\mathrm{a}}$} \\
\hline Cohort (PVA vs CV control) & $<0.0001$ & $0.3(0.2-0.5)$ \\
\hline Age & $<0.000$ I & I.I (I.I-I.I) \\
\hline Cardiomyopathy & 0.0449 & $4.3(1.0-17.5)$ \\
\hline Chronic kidney disease & 0.0103 & $3.4(1.3-8.5)$ \\
\hline $\begin{array}{l}\text { Chronic obstructive pulmonary } \\
\text { disease }\end{array}$ & 0.0010 & $4.1(1.8-9.4)$ \\
\hline Coronary artery bypass graft & 0.0303 & $4.9(1.2-20.5)$ \\
\hline Hemorrhagic stroke & 0.0061 & $15.9(2.2-|| 4.2)$ \\
\hline
\end{tabular}

Notes: ${ }^{\mathrm{A}} \mathrm{Age}$ is at the index date and all comorbid conditions include diagnoses within 3 years prior.

Abbreviations: AF, atrial fibrillation; $\mathrm{CV}$, cardioversion; PVA, pulmonary vein ablation.

As expected, prior stroke/TIA is a statistically significant predictor of stroke/TIA survival, and prior heart failure is a significant predictor of heart failure hospitalization, regardless of the matched population. The association with a prior similar event is stronger for heart failure $(p<0.0001, \mathrm{HR}=24.6$ for the $\mathrm{PVA} /$ general AF match; $p<0.0001, \mathrm{HR}=6.8$ for the $\mathrm{PVA} /$ cardioversion match) than for stroke/TIA ( $p=0.0004, \mathrm{HR}=4.1$ for the $\mathrm{PVA} /$ general AF match; $p=0.0052, \mathrm{HR}=3.0$ for the PVA/ cardioversion match). Cohort and age are predictive of all three outcomes, with the HR for age based on each 1-year increase. Most components of the $\mathrm{CHA}_{2} \mathrm{DS}_{2}$-VASc score are also significant predictors of stroke/TIA survival. In addition to some of the same risk factors seen in the stroke and heart failure models, chronic kidney disease and chronic obstructive pulmonary disease were highly significant predictors of death in hospital for both matched populations (Tables 2-4).

\section{Discussion}

Among 5,000 patients undergoing PVA, we found that the rates of mortality, heart failure, and stroke/TIA were all significantly lower than in very well-matched cohorts of 
cardioversion and general AF patients. The HR for individual outcomes with PVA was between 0.1 and 0.6 compared with other cohorts.

Although PVA is superior to drugs in maintaining sinus rhythm, ${ }^{8,9}$ large randomized trials have not yet reported on whether this improves clinical outcomes. Several studies reporting anticoagulation discontinuation after successful PVA have demonstrated very low stroke rates. ${ }^{22-25}$ Other studies have shown continued higher stroke rates after cardioversion and antiarrhythmic drugs. ${ }^{5}$ In addition, PVA appears to prevent progression of paroxysmal to persistent $\mathrm{AF}^{26}$ a progression associated with increased stroke and mortality. ${ }^{27,28}$ Freedom from AF following PVA is the most powerful predictor of stroke- and death-free survival, which have been shown to occur at rates comparable to age- and sex-matched controls without AF. ${ }^{29}$ Additionally, randomized trials have shown significant improvements in key clinical outcomes after PVA versus rate control in heart failure patients. ${ }^{30}$

Several retrospective cohort studies have shown consistent results. An early study found lower rates of death, stroke, and dementia in 4,212 PVA patients than in age- and sexmatched AF controls, comparable to controls without AF. ${ }^{14}$ Matching the same PVA cohort by age, sex, and $\mathrm{CHADS}_{2}$ score also demonstrated stroke rates lower than a general AF population and comparable to a population without AF. ${ }^{15}$ An initial propensity-matched study comparing 801 patients with PVA between 2005 and 2009 to general AF patients demonstrated significantly lower stroke rates and a nonsignificant reduction in heart failure hospitalization, ${ }^{16}$ whereas another with 846 matched pairs between 2003 and 2009 found lower rates of stroke and nonsignificant reductions in death and heart failure hospitalization. ${ }^{17}$ Most recently, a propensity-matched study compared 12,122 PVA patients with cardioversion patients and found a significantly lower stroke rate in the PVA group. ${ }^{18}$

This study is notable for the very large PVA cohorts and the quality of the matching across many key baseline risk factors. The significant predictors of all three outcomes identified by Cox regression analysis were highly intuitive (for instance, including almost all elements of the $\mathrm{CHA}_{2} \mathrm{DS}_{2}-$ VASc score for the stroke/TIA outcome), thus providing a level of validation for the quality of the methodology. The PVA population was also contemporary, with over half of the procedures in 2012 or later.

This is the first propensity-matched analysis to demonstrate significantly lower rates of heart failure hospitalization and death after catheter ablation of AF compared to control cohorts. It is also the first to examine these outcomes relative to a cardioversion cohort. The HRs and significance levels demonstrated a greatly reduced risk for all measured outcomes after PVA compared to matched AF patients (stroke/ TIA: $\mathrm{HR}=0.4, p<0.001$; heart failure: $\mathrm{HR}=0.4, p<0.001$; death: $\mathrm{HR}=0.1, p<0.001)$ and to matched cardioversion patients (stroke/TIA: $\mathrm{HR}=0.6, p=0.0111$; heart failure: $\mathrm{HR}=0.4, p<0.001$; death: $\mathrm{HR}=0.3, p<0.001)$.

\section{Limitations}

The primary limitations are the risk of confounding by unmeasured variables and the lack of clinical detail because of the retrospective data source. However, the quality of matching was very high, the effect sizes were large, and the results were consistent with other studies. Another limitation relevant to the stroke/TIA outcome is the lack of data on anticoagulation. Inclusion of a cardioversion group helps to mitigate this limitation, and it is notable that in similar cohort studies where anticoagulant data were available, rates of usage in the baseline PVA and general AF cohorts were nearly identical. ${ }^{16,17}$ A further limitation is the lack of primary care data, which may result in underestimated comorbidity rates, $\mathrm{CHA}_{2} \mathrm{DS}_{2}$-VASc scores, and outcomes, though we would expect any effect to be proportionate across cohorts. Despite tight cohort matching and exploration of multiple key endpoints, residual confounding due to unmeasured variables remains a potential limitation.

\section{Conclusion}

In large and well-matched cohorts of UK patients with AF, catheter ablation was associated with significantly lower rates of stroke/TIA, heart failure hospitalization, and death than in patients who did not undergo ablation, including those who underwent cardioversion.

\section{Acknowledgments}

Biosense Webster provided funding for data collection, statistical analysis, and medical writing. The Cardiovascular Biomedical Research Unit, Royal Brompton \& Harefield NHS Foundation Trust supported data analysis, drafting, and revision work of JWEJ, WH, TW, and VM.

\section{Disclosure}

TDH is an employee of CTI Clinical Trial \& Consulting Services, Inc., which is a paid consultant to Biosense Webster. JLM is a paid employee of Biosense Webster. VM reports personal fees from Biosense Webster, outside the submitted work. The authors report no other conflicts of interest in this work. 


\section{References}

1. Benjamin EJ, Wolf PA, D’Agostino RB, Silbershatz H, Kannel WB, Levy D. Impact of atrial fibrillation on the risk of death: the Framingham Heart Study. Circulation. 1998;98(10):946-952.

2. Wolf PA, Abbott RD, Kannel WB. Atrial fibrillation as an independent risk factor for stroke: the Framingham Study. Stroke. 1991;22(8):983-988.

3. Wang TJ, Larson MG, Levy D, et al. Temporal relations of atrial fibrillation and congestive heart failure and their joint influence on mortality: the Framingham Heart Study. Circulation. 2003;107(23):2920-2925.

4. Freeman JV, Simon DN, Go AS, et al. Association between atrial fibrillation symptoms, quality of life, and patient outcomes: results from the Outcomes Registry for Better Informed Treatment of Atrial Fibrillation (ORBIT-AF). Circ Cardiovasc Qual Outcomes. 2015;8(4):393-402.

5. Wyse DG, Waldo AL, DiMarco JP, et al. A comparison of rate control and rhythm control in patients with atrial fibrillation. $N$ Engl J Med. 2002;347(23):1825-1833.

6. Corley SD, Epstein AE, DiMarco JP, et al. Relationships between sinus rhythm, treatment, and survival in the Atrial Fibrillation Follow-Up Investigation of Rhythm Management (AFFIRM) Study. Circulation. 2004;109(12):1509-1513.

7. Hohnloser SH, Crijns HJ, van Eickels M, et al. Effect of dronedarone on cardiovascular events in atrial fibrillation. $N$ Engl J Med. 2009;360(7):668-678

8. Noheria A, Kumar A, Wylie JV Jr, Josephson ME. Catheter ablation vs antiarrhythmic drug therapy for atrial fibrillation: a systematic review. Arch Intern Med. 2008;168(6):581-586.

9. Wynn GJ, Das M, Bonnett LJ, Panikker S, Wong T, Gupta D. Efficacy of catheter ablation for persistent atrial fibrillation: a systematic review and meta-analysis of evidence from randomized and nonrandomized controlled trials. Circ Arrhythm Electrophysiol. 2014;7(5): 841-852.

10. Cappato R, Calkins H, Chen SA, et al. Updated worldwide survey on the methods, efficacy, and safety of catheter ablation for human atrial fibrillation. Circ Arrhythm Electrophysiol. 2010;3(1):32-38.

11. Pappone C, Rosanio S. Evolution of non-pharmacological curative therapy for atrial fibrillation. Where do we stand today? Int J Cardiol. 2003;88(2-2):135-142.

12. Camm AJ, Lip GY, De Caterina R, et al. 2012 focused update of the ESC Guidelines for the management of atrial fibrillation: an update of the 2010 ESC Guidelines for the management of atrial fibrillation. Developed with the special contribution of the European Heart Rhythm Association. Eur Heart J. 2012;33(21):2719-2747.

13. January CT, Wann LS, Alpert JS, et al. 2014 AHA/ACC/HRS guideline for the management of patients with atrial fibrillation: executive summary: a report of the American College of Cardiology/American Heart Association Task Force on practice guidelines and the Heart Rhythm Society. Circulation. 2014;130(23):2071-2104.

14. Bunch TJ, Crandall BG, Weiss JP, et al. Patients treated with catheter ablation for atrial fibrillation have long-term rates of death, stroke, and dementia similar to patients without atrial fibrillation. $J$ Cardiovasc Electrophysiol. 2011;22(8):839-845.

15. Bunch TJ, May HT, Bair TL, et al. Atrial fibrillation ablation patients have long-term stroke rates similar to patients without atrial fibrillation regardless of CHADS2 score. Heart Rhythm. 2013;10(9):1272-1277.
16. Reynolds MR, Gunnarsson CL, Hunter TD, et al. Health outcomes with catheter ablation or antiarrhythmic drug therapy in atrial fibrillation: results of a propensity-matched analysis. Circ Cardiovasc Qual Outcomes. 2012;5(2):171-181.

17. Chang CH, Lin JW, Chiu FC, Caffrey JL, Wu LC, Lai MS. Effect of radiofrequency catheter ablation for atrial fibrillation on morbidity and mortality: a nationwide cohort study and propensity score analysis. Circ Arrhythm Electrophysiol. 2014;7(1):76-82.

18. Noseworthy PA, Kapa S, Deshmukh AJ, et al. Risk of stroke after catheter ablation versus cardioversion for atrial fibrillation: a propensity-matched study of 24,244 patients. Heart Rhythm. 2015;12(6):1154-1161.

19. Gage BF, Waterman AD, Shannon W, Boechler M, Rich MW, Radford MJ. Validation of clinical classification schemes for predicting stroke: results from the National Registry of Atrial Fibrillation. JAMA. 2001;285(22):2864-2870.

20. Lip GY, Nieuwlaat R, Pisters R, Lane DA, Crijns HJ. Refining clinical risk stratification for predicting stroke and thromboembolism in atrial fibrillation using a novel risk factor-based approach: the euro heart survey on atrial fibrillation. Chest. 2010;137(2):263-272.

21. Mayo Clinic. [website on the Internet]. Gmatch macro developed by Erik Bergstralh and Jon Kosanke. 10/2003. Available from: http:// www.mayo.edu/research/departments-divisions/department-healthsciences-research/division-biomedical-statistics-informatics/software/ locally-written-sas-macros. Accessed January 31, 2016.

22. Winkle RA, Mead RH, Engel G, Kong MH, Patrawala RA. Discontinuing anticoagulation following successful atrial fibrillation ablation in patients with prior strokes. J Interv Card Electrophysiol. 2013;38(3):147-153

23. Saad EB, d'Avila A, Costa IP, et al. Very low risk of thromboembolic events in patients undergoing successful catheter ablation of atrial fibrillation with a CHADS2 score $\leq 3$ : a long-term outcome study. Circ Arrhythm Electrophysiol. 2011;4(5):615-621.

24. Riley MP, Zado E, Hutchinson MD, et al. Risk of stroke or transient ischemic attack after atrial fibrillation ablation with oral anticoagulant use guided by ECG monitoring and pulse assessment. J Cardiovasc Electrophysiol. 2014;25(6):591-596.

25. Themistoclakis S, Corrado A, Marchlinski FE, et al. The risk of thromboembolism and need for oral anticoagulation after successful atrial fibrillation ablation. J Am Coll Cardiol. 2010;55(8):735-743.

26. Proietti R, Hadjis A, AlTurki A, et al. A systematic review on the progression of paroxysmal to persistent atrial fibrillation. Shedding new light on the effects of catheter ablation. JACC Clin Electrophysiol. 2015;1(3):105-115.

27. Steinberg BA, Hellkamp AS, Lokhnygina Y, et al. Higher risk of death and stroke in patients with persistent vs. paroxysmal atrial fibrillation: results from the ROCKET-AF Trial. Eur Heart J. 2015;36(5):288-296.

28. Glotzer TV, Daoud EG, Wyse DG, et al. The relationship between daily atrial tachyarrhythmia burden from implantable device diagnostics and stroke risk: the TRENDS study. Circ Arrhythm Electrophysiol. 2009;2(5):474-480.

29. Hunter RJ, McCready J, Diab I, et al. Maintenance of sinus rhythm with an ablation strategy in patients with atrial fibrillation is associated with a lower risk of stroke and death. Heart. 2012;98(1):48-53.

30. Al Halabi S, Qintar M, Hussein A, et al. Catheter ablation for atrial fibrillation in heart failure patients: a meta-analysis of randomized controlled trials. JACC Clin Electrophysiol. 2015;1(3):200-209.
Pragmatic and Observational Research

\section{Publish your work in this journal}

Pragmatic and Observational Research is an international, peer-reviewed, open access journal that publishes data from studies designed to reflect more closely medical interventions in real-world clinical practice compared with classical randomized controlled trials (RCTs). The manuscript management system is completely online and includes a very quick and fair peer-review

\section{Dovepress}

system. Visit http://www.dovepress.com/testimonials.php to read real quotes from published authors. 